\title{
A Study on the Effect of Features Obtained from Signal Segments on Classification Success
}

\author{
Erdem Erkan ${ }^{1}$, Yasemin Erkan ${ }^{2 *}$ \\ ${ }^{1}$ Bartın University, Faculty of Engineering Arcitecture and Design, Departmant of Computer Engineering, Bartın, Turkey, (ORCID: 0000-0002-2386-1271), \\ eerkan@bartin.edu.tr \\ 2* Bartın University, Faculty of Engineering Architecture and Design, Departmant of Electric-Electronic Engineering, Bartın, Turkey, (ORCID: 0000-0002-5825-2177), \\ yerkan@bartin.edu.tr
}

(International Conference on Design, Research and Development (RDCONF) 2021 - 15-18 December 2021)

(DOI: $10.31590 /$ ejosat.1040429)

ATIF/REFERENCE: Erkan E., Erkan Y., (2021). A study on the Effect of Features Obtained from Signal Segments on Classification Success. European Journal of Science and Technology, (32), 383-391.

\begin{abstract}
Successful classification depends on the selection of the distinctive features and the effective channel subset used in the classification. In this study, novel and practical methods are proposed for determining the distinctive features and detecting effective channel subsets in the multi channel classification systems such as EEG. Two different feature extraction methods are compared in the study. The first one is based on classical Wavelet transform and the second is our proposed approach which used the slope of signal segments. Feature vectors are generated from some signal properties such as the mean, standard deviation, numerical integral of the Wavelet coefficients for classical Wavelet transform based feature extraction method. For our proposed method, only the slopes of signal segments are used for the feature vectors. In the proposed Signal Path Slope (SPS) feature extraction method, differently from the classical Wavelet based method, a Savitzky Golay (S-G) filter with an optimal frame length is applied to the signal before segmentation to make the path of the signal more prominent in time domain. In this way, the distinctive classification features are extracted by using $S-G$ filter. For channel selection, an iterative channel selection method based on the classification results which divide the dataset labelled dataset into two groups as \% 90 pre-training and \%10 pre-test data is proposed. The dataset provided as dataset-3 in BCI competition IV is used in this study. The feature vectors extracted by using the proposed methods are classified for each method with the Support Vector Machine classifier. The results are given comparatively and it is observed that our proposed method has less computational complexity and more successful classification than Wavelet based classical feature extraction methods. The highest classification accuracies of $\% 67.74$ and $\% 49.27$ for subject-1 and subject- 2 respectively are obtained with a low dimensional feature vector by proposed SPS feature extraction method. The classification accuracies achieved in the study are increased by $\% 8.24$ for subject-1 and \% 14.97 for subject-2 when compared average of the competition results. The significant increase in the success for both subjects shows the consistency of the proposed methods. By this study, it is observed that there is a subject-specific signal pattern related to motor imagery tasks in the brain. This pattern distinctive features is successfully determined by using the proposed methods.
\end{abstract}

Keywords: Brain Computer Interface, Classification, Feature Vector, Channel Selection, Savitzky Golay.

\section{Sinyal Segmentlerinden Elde Edilen Özniteliklerin Sınıflandırma Başarısına Etkisi Üzerine Bir Araştırma}

Öz

Başarılı sınıflandırma, ayırt edici özniteliklerin ve sınıflandırmada kullanılan etkin kanal alt kümesinin seçimine bağlıdır. Bu çalışmada, EEG gibi çok kanallı sınıflandırma sistemlerinde ayırıcı özniteliklerin belirlenmesi ve etkin kanal alt kümelerinin saptanması için yeni ve pratik yöntemler önerilmiş ve iki farklı öznitelik çıkarma yöntemi karşılaştırılmıştır. Bunlardan ilki, klasik Dalgacık dönüşümüne ve ikincisi de sinyal segmentlerinin eğimini kullanan önerilen yaklaşımımızdır. Klasik Dalgacık dönüşümü tabanlı öznitelik çıkarma yöntemi için Dalgacık katsayılarının ortalama, standart sapma, sayısal integrali gibi bazı sinyal özelliklerinden öznitelik vektörleri üretilir. Önerilen, Sinyal Yolu Eğimi (SPS) yöntemi için ise öznitelik vektörleri sadece sinyal segmentlerinin eğimlerinden

${ }^{*}$ Corresponding Author: yerkan@bartin.edu.tr 
oluşmaktadır. Önerdiğimiz öznitelik çıkarma yönteminde, klasik Dalgacık tabanlı yöntemden farklı olarak, segmentasyondan önce sinyale zaman domeninde optimal çerçeve uzunluğuna sahip bir Savitzky Golay (SG) filtresi uygulanarak sinyal yolunun daha belirgin hale getirilmesi sağlanmıştır. Bu sayede SG filtresi kullanılarak ayırt edici sınıflandırma öznitelikleri çıkarılmaktadır. Kanal seçimi için, eğitim veri kümesi \%90 ön eğitim ve \%10 ön test verisi olarak iki gruba ayıran iteratif bir kanal seçim yöntemi önerilmiştir. Çalışmada BCI yarışması IV'te sunulan veri seti-3 kullanılmıştır. Önerilen yöntemler kullanılarak çıkarılan öznitelik vektörleri Destek Vektör makinesi sınıflandırıcısına tabi tutulmuştur. Sonuçlar karşılaştırmalı olarak verilmiş ve önerilen yöntemimizin Wavelet tabanlı klasik öznitelik çıkarma yöntemlerine göre daha az hesaplama karmaşıklığına ve daha başarılı sınıflandırma kabiliyetine sahip olduğu gözlemlenmiştir. Denek-1 ve denek-2 için sırasıyla \% 67.74 ve \% 49.27 olan en yüksek sınıflandırma doğruluğu, önerilen SPS öznitelik çıkarma yöntemi ile düşük boyutlu bir öznitelik vektörü ile elde edilmiştir. Çalışmada elde edilen sınıflandırma başarımı, yarışma elde edilen sonuçlarla karşılaştırıldığında, denek-1 için \% 8.24 ve denek-2 için \% 14.97 oranında sınıflandırma başarısı artışı gözlemlenmiştir. Her iki denek için de başarıdaki önemli artış, önerilen yöntemlerin tutarlılığını göstermektedir. Bu çalışma ile beyinde motor imgeleme görevleriyle ilgili deneğe özgü bir sinyal örüntüsü olduğu gözlemlenmiştir. Bu örüntünün ayırt edici özellikleri önerilen yöntemler kullanılarak başarılı bir şekilde tespit edilmiştir.

Anahtar Kelimeler: Beyin Bilgisayar Arayüzü, Sınıflandırma, Öznitelik Vektörü, Kanal Seçimi, Savitzky Golay.

\section{Introduction}

The investigation of psychophysiological signals such as Magnetoencephalography (MEG) and Electroencephalography (EEG) has become very popular research area by the desire to explore human brain. Researchers have been trying to classify psychophysiological signals to understand and learn the nature of life. The most important factor affecting the classification success is the determination of the distinctive features used in classification. In the literature, various mathematical procedures such as Wavelet transform [1-3], Fourier transform [4], autoregressive model [5] and common spatial pattern [6-9] have been used to determine the most efective distinctive features from the psychophysiological signals. The main purpose of classification is to clean the unnecessary data and make the most effective classification with the most optimal number of features. It is also important to determine the effective channel subset in multi channel signals such as EEG [10, 11]. Each channel determined by channel selection increases the feature size by one fold. High dimensional feature vector space increases the classification computational time and complexity.

Briefly, the success of the entire system is determined by the distinctive features, channel subset and preferred classifier method. Popular classification methods such as K-Nearest Neighbors (KNN) algorithm [12], Support Vector Machines (SVM) [13-16], Linear Discriminant Analysis (LDA) [6-8,17,18] and artificial neural networks [19-24] have been widely applied BCI classifications in the literature.

In this study, novel and practical approach which use signal differentiation property of the Savitzky Golay (S-G) filter [25] and slope of the signal segements has been proposed to determine the distinctive features. Channel subset used in the classification is also determined by an iterative channel selection method based on Kappa coefficient [26].

The proposed method is tested on dataset- 3 consisting of Magnetoencephalography (MEG) signals in BCI competition IV. The MEG dataset was recorded from two healty and right handed subjects during the wrist movements in four directions (in the horizontal plane with corners pointing left, right, away from and toward the subject's body). The participants were tried to predict the class labels for unlabeled evulation data consisted of 74 and 73 trials for subject- 1 and subject- 2 respectively using the labelled training data which included 40 trials per class for each subject [27,28]. Sardouie and Shamsollahi from Sharif University achieved the highest classification success in the competition among 4 participant groups with \% 46.9 (S1= \%59.5, S2=\%34.3) accuracy rate. They extracted frequency domain features and wavelet coefficients from 12 channels (10 real channels plus 2 artificial bipolar channels) for feature set. They reduced the number of features using a supervised algorithm. They also used a genetic algorithm selected features to optimize the classification accuracy. Then they have used a combination of a linear SVM and LDA for classification [27]. $\mathrm{Li}$ et al. were second in the competition by $\% 25.1$ ( $\mathrm{S} 1=\% 31.1, \mathrm{~S} 2=\%$ 19.2) accuracy rate. They used a $8 \mathrm{~Hz}$ low pass filter to filter the signal. They selected the time segment between $0-0.5 \mathrm{~s}$. Then, they used principal components (first three and five) of the abs and angle of the 128 fast Fourier transform of each channel and each sample for feature vector. They reduce the dimension of the frequency features by using FDA and subsampled the signal to $20 \mathrm{~Hz}$. They also used the combination of time and frequency features for the Fisher discriminant classification [28]. Montazeri and Shamsollahi composed a feature set consisted of statistical, temporal, parametric and Wavelet coefficients and they reduced it set by principal component analysis and a genetic algorithm. They used a linear SVM classifier. They achieved \% 23.9 (S1=\% 16.2, S2=\% 31.5 ) accuracy rate [28]. Wang and Zhang first applied a $8 \mathrm{~Hz}$ low pass filter to the signal. Secondly, They selected 0-0.5 second time segment. Third, they used principal components (first three and five ) of the abs and angle of the 128 fast Fourier transform of each channel and each sample. Then, they applied Fisher Discriminant Analysis to reduce dimensionality. Finally, they used frequency features in the classification. They achieved \% $20.4(\mathrm{~S} 1=\%$ 23.0, S2=\% 17.8) accuracy rate [28].

In order to test performance of the proposed method, feature vectors calculated by two different feature extraction methods such as classical Wavelet coefficients and the proposed Signal Path Slope (SPS) feature extraction approach were classified with linear SVM classifier. The results were presented comparatively.

The SPS method segments the EEG signals and calculates slopes for each segments. The feature vectors have only one slope feature for each signal segment. Therefore, the method has low computational complexity with a low-dimensional feature vector. As a result, it is achieved successful classification results by the proposed SPS method for MEG dataset. In the tests performed 
using the MEG dataset, the highest classification accuracies of \% 67.74 for subject- 1 and $\% 49.27$ for subject- 2 are obtained for both subjects.

\section{Material and Method}

\subsection{Datasets}

In order to test the proposed methods in this study, it is used dataset which are dataset-3 consisting of Magnetoencephalography (MEG) signals in BCI competition IV.

\subsubsection{MEG Dataset}

The dataset which were provided as dataset-3 in BCI competition IV is used in this study. The dataset was recorded from two healty subjects by using ten MEG channels which were located above the motor areas. During the experiment, a subject had to perform wrist movements in four directions in the horizontal plane with corners pointing left, right, away from and toward the subject's body. All recordings were performed with a sampling rate of $625 \mathrm{~Hz}$. The trials were cut to contain data from $0.4 \mathrm{~s}$ before to $0.6 \mathrm{~s}$ after movement onset and the signals were band pass filtered $(0.5$ to $100 \mathrm{~Hz})$ and resampled at $400 \mathrm{~Hz}$. The participants were tried to predict the class labels for unlabeled evulation data which were comprised of 74 and 73 trials for subject-1 and subject- 2 respectively using the labelled training data which included 40 trials per class for each subject. The highest classification success was demonstrated \% 46.9 (S1=\% $59.5, \mathrm{~S} 2=\% 34.3$ ) accuracy rate by Sardouie and Shamsollahi from Sharif University [27,28].

First, we examined the average of training data given with MEG dataset in time domain to observe the time pattern of each classes. The average of training data given MEG dataset for subject-1 are given for each classes in Figure 1.

To analyze the differencies of classes, we applied 5th-order S-G filter which has different FL's to the average of training data for each class. The FL represents the frame length of the S-G filter. For example the S-G filter outputs of the average training data of class- 1 for subject-1 are presented In Figure 2. The FL is selected as 31, 81, 171 and 341 respectively in Figure 2.

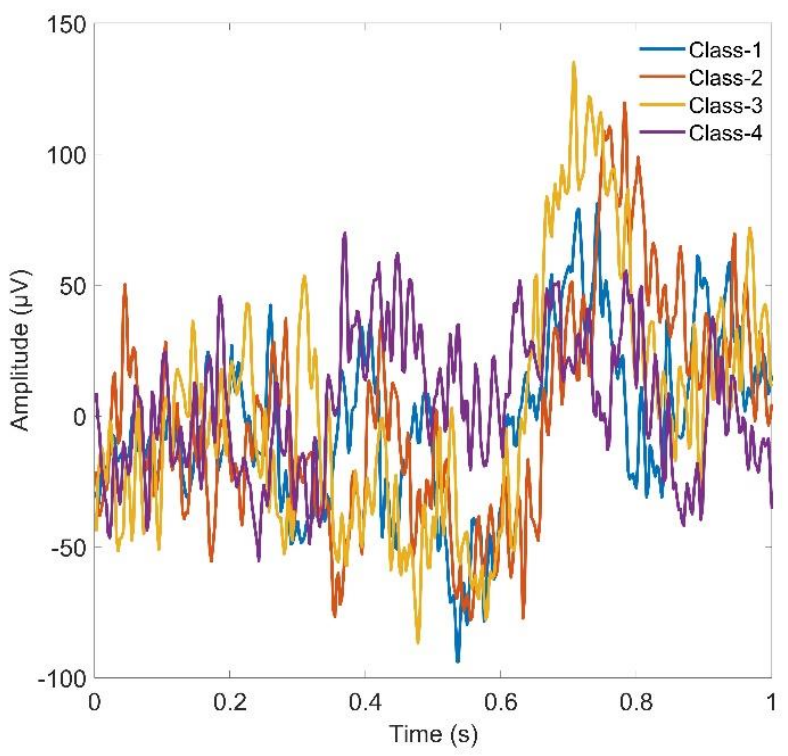

Figure 1. The average of training data given MEG dataset for subject-1.(channel number=4).

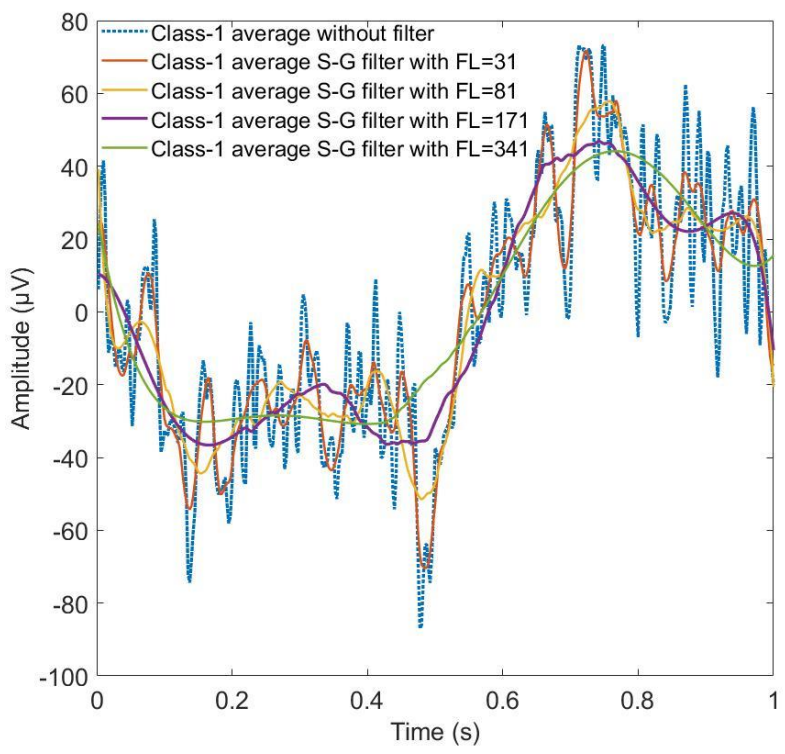

Figure 2. The S-G filter outputs of the average training data of class-1 for subject-1. (channel number=4).

As seen in Figure 2, the optimum S-G filter frame length is determined as 171 . The S-G- filter output with selected frame length shows maximum consistency with the original signal. The S-G filter outputs of the average training data of subject-1 are given for each class in Figure 3.

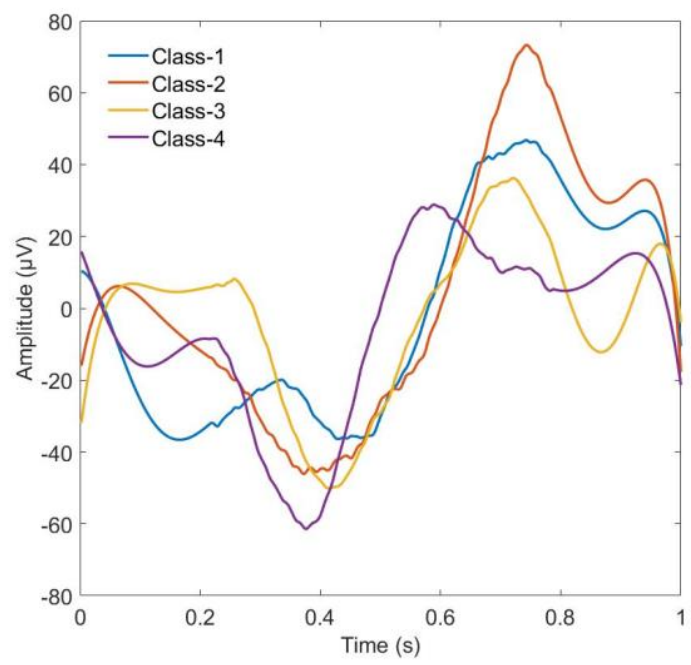

Figure 3. The S-G filter outputs of the average training data of subject-1 for each class. ( $F L=171)$.

Starting from this point, the S-G filter outputs of the trials in the relevant dataset are segmented and the feature vectors used in the classification are calculated from each segment. To detection of number of the signal segments, number of the abrupt slope changes in the filtered signal average of all classes are detected. For this we used "findchangepts" command in Matlab. In this way, it is determined number of the signal segments. For average of the all classes, abrupt slope changings of the MEG dataset are given by Figure 4. 


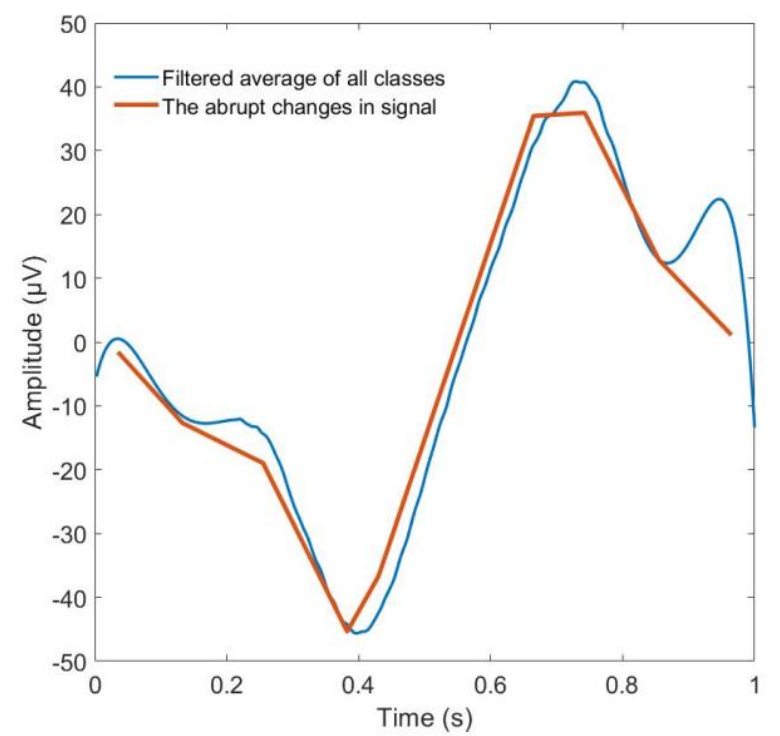

Figure 4. The detection of number of the signal segments.

\subsection{Feature Extraction}

To compare proposed method, another classical feature extraction approach based on Wavelet transform is also used. In both of the methods, in order to obtain the distinctive features of the pattern in the time domain, the trial signals are segmented and feature vectors are extracted with the calculated features from each part of the signal

\subsubsection{Signal Path Wavelet (SPW)}

This feature extraction methos is based on Wavelet Transform (WT), which is a technique that allows to model variations in EEG signals, within the scale time domain. This transformation method is widely applied in science and engineering fields for solving various real life problems.In the SPW method, the WT is used to extract features used in classification from signal segments. The WT preserve time and frequency characteristics of the signal. The WT represents a signal as a weighted sum of shifted and scaled versions of a Wavelet function. The $\psi$ and $W C$ represents the Wavelet function and WT Coefficients in Equation 1 respectively.

$$
W C(\text { Scale, Position }) \int_{-\infty}^{+\infty} x(t) \psi(\text { Scale, Position }(t) d t)
$$

When the scales and shifts of the WT are selected with the base equal to 2, the tranform is called as Discrete Wavelet Transform (DWT) which much more effective. The DWT is given by Equation 2. [2, 3].

$$
\operatorname{DWT}(i, l)=\sum_{i} \sum_{l} x(l) 2^{-\frac{i}{2}} \psi\left(2^{-i} n-l\right)
$$

The DWT coefficients are calculated from 6th order transform which is used Daubechies Wavelet function. Each trial of signal divided eight parts and this transforms applied to the all parts of the signal separately. With this method, DWT is applied to sequential time segments of the signal and the features such as mean, standard deviation and numerical integration are calculated from Wavelet coefficients. Equation 3 is used to calculate numerical integration [29].

$$
\int_{a}^{b} S(t) d t=\frac{1}{2}(b-a)(S(a)+S(b))
$$

By Figure 5, the Wavelet coefficients applied to each segment of signal are given and coefficients used in calculations e-ISSN: 2148-2683 highlighted. These coefficients are selected considering the frequency band of the EEG signals. Each signal segments corresponds to 50 points $(\mathrm{Fs}=400 \mathrm{~Hz})$. An example training signal segmented for subject-1 of MEG dataset is given by Figure 6 . The $S$ represents second segment. The feature vector is generated with $24(8 \times 3)$ features calculated from each signal segment for a channel. 8 Wavelet coefficients in the EEG frequency band were used in the calculations.

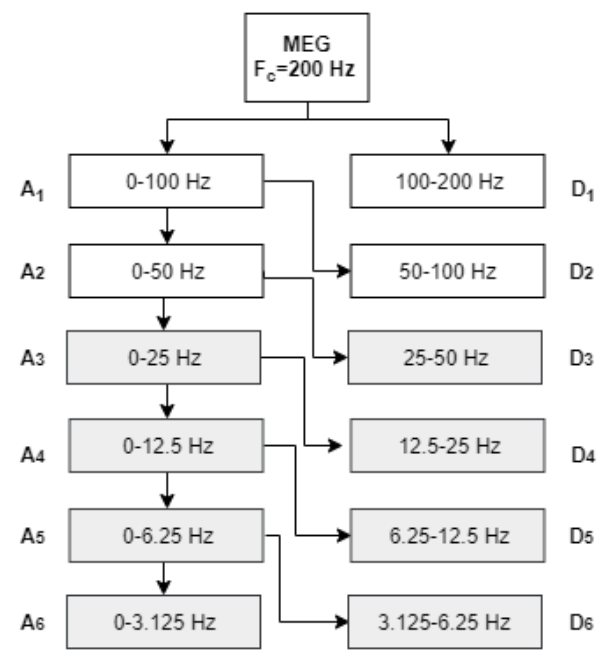

Figure 5. The DWT levels of the MEG dataset. $(\mathrm{Fs}=400 \mathrm{~Hz})$

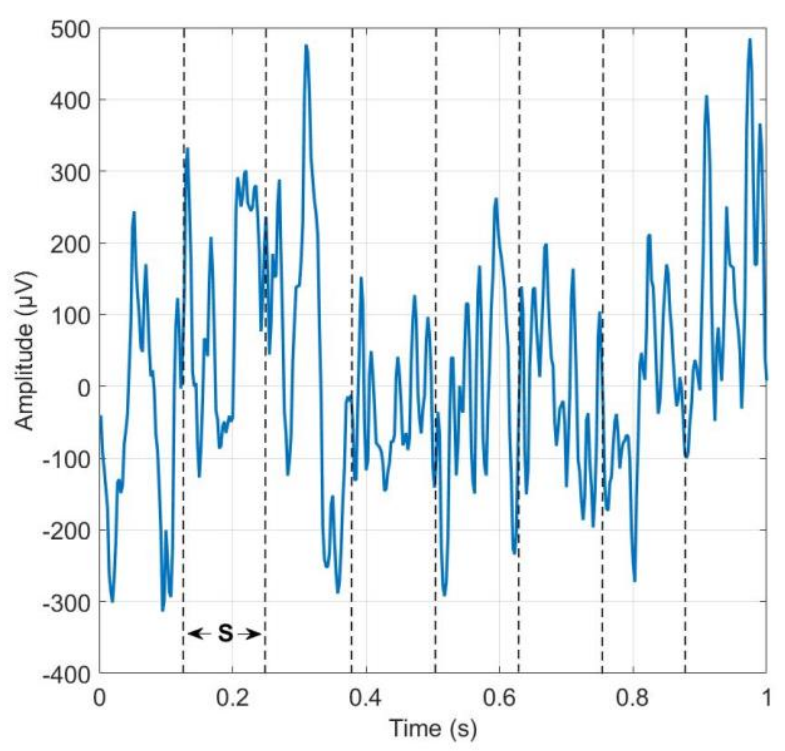

Figure 6. The signal segments of SPW on MEG dataset. (Trial 4 on channel 6 for class 3).

\subsubsection{Signal Path Slope (SPS)}

The proposed method is inspired by the pattern of the signal in time domain. Differently from the previous method, the signal is filtered by Savitzky Golay (S-G) filter to make the path of the signal more prominent in time domain. The S-G filter is a finite impulse response smoothing filter which is also known as polynomial-smoothing, or least-squares-smoothing filter [25]. The S-G filter works by differentiation of a moving window of least squares polynomial fit using a table of convolution coefficients [30]. The Equation 4 defines the general filter equation according to the S-G filter. The particular behavior of the filter can be incfluenced by chosing appropriate filter coefficients. The parameter $m$ defines the number of data points used for the 
smoothing. The $C_{i}$ represent any set of convoluting integers and $h$ is the number of convoluting integers. The $C_{i}$ and $h$ values can obtain from table of convolution coefficients $[25,30]$.

$$
y^{j *}=1 / h \sum_{i=-\frac{m-1}{2}}^{\frac{m-1}{2}} C_{i} y_{j+1}
$$

The S-G filters are widely used to smoothing and differentiation in psychophysiological signal processing [31-34]. Figure 7 and Figure $8 \mathrm{a}, \mathrm{b}, \mathrm{c}$, and d presents the mean of class 1, class 2, class 3, and class 4 in the MEG dataset of subject-1 and subject-2 for channel 4 , respectively. The high frequency blue and red lines in the figure show the averages of the training and test data and the low frequency yellow and purple lines show the S-G filter outputs of these data. In Figure 7 and Figure 8, it is clear that, the average of the training and test trials exhibits a similar pattern for each class.

In the proposed method, differently from the literature, we determined the time path of the EEG by a S-G smoothing filter designed which has with optimal Frame Length (FL). The FL has to be odd number for S-G filters [25]. For proposed SPS feature extraction method, the S-G filter level and FL are selected as 5 and 171 respectively. The slope ratio which used in many engineering fields such as fingerprint detection and face recognition studies $[35,36]$ in the literature, characterizes the direction of a line. Therefore, the feature vectors are extracted by calculating the slope of each sequential time segments of the smoothed signal. The feature vector is generated with only 1 features calculated from each signal segment for a channel. The proposed SPS method flow diagram is given in Figure 9. By the Figure 10, sample trial signal, filtered signal, signal segments and the slope of lines are illusturated.

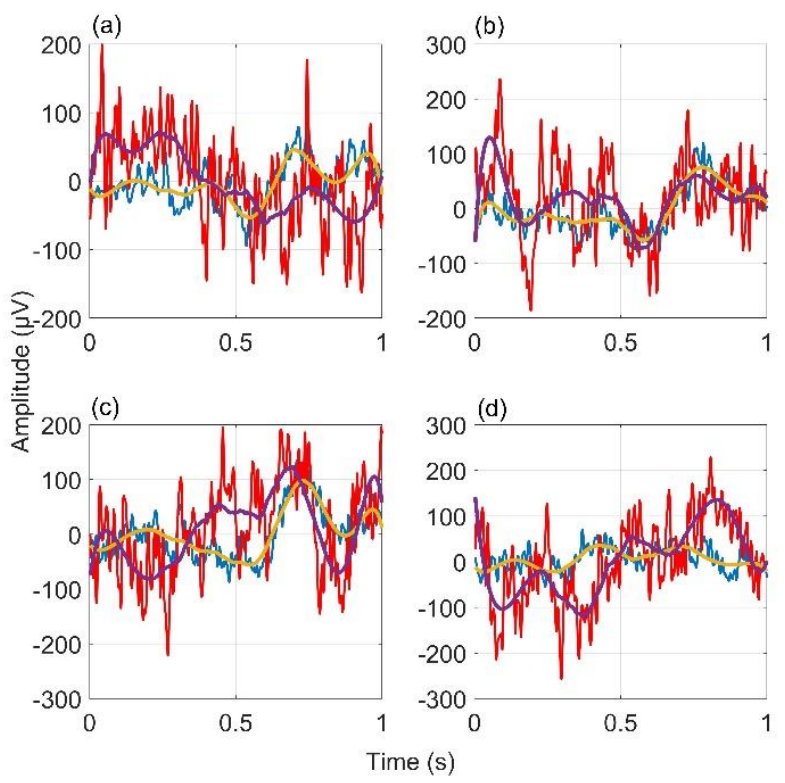

Figure 7. Training and test averages of MEG dataset for subject-1, channel 4.

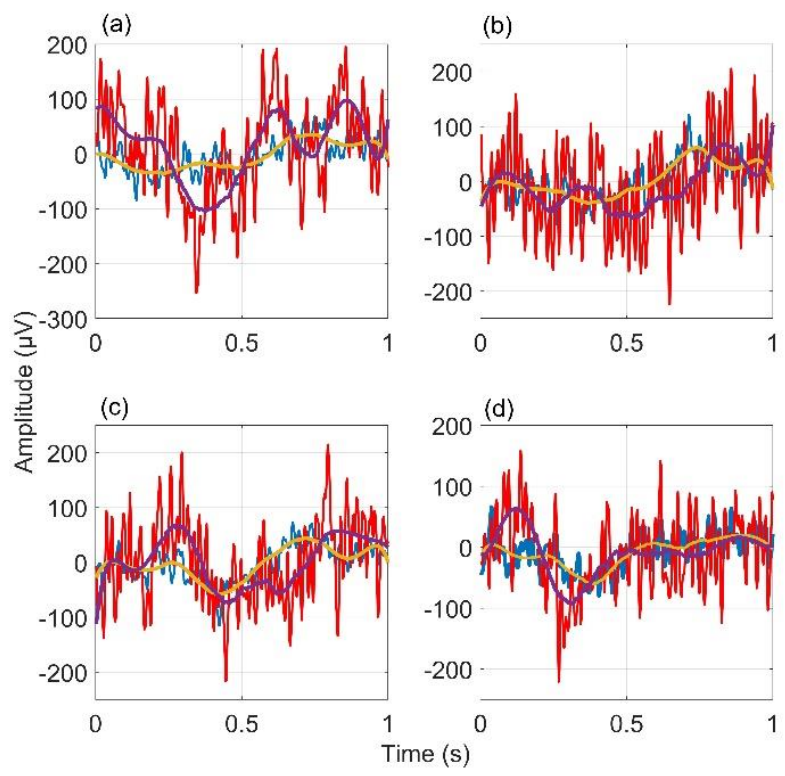

Figure 8. Training and test averages of MEG dataset for subject-2, channel 4 .

$$
S=\left(y_{2}-y_{1}\right) /\left(x_{2}-x_{1}\right)
$$

The calculation of the slope for line given its two points is given by Equation 5. The $S$ represents the slope, $\left(x_{1}, y_{1}\right)$ are the $x-y$ components of the first point and $\left(x_{2}, y_{2}\right)$ are the $x-y$ components of the second point [37]. By Equation 5, the path of the signal over time is transferred to the feature vector by calculating the slope of each signal segment. This path has distinctive features for all classes in the dataset.

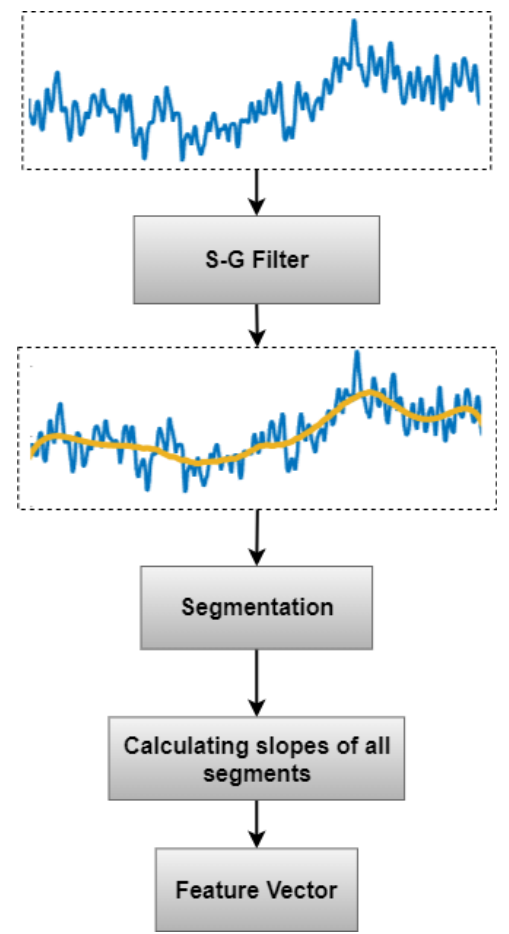

Figure 9. Slope features of the time segments. 


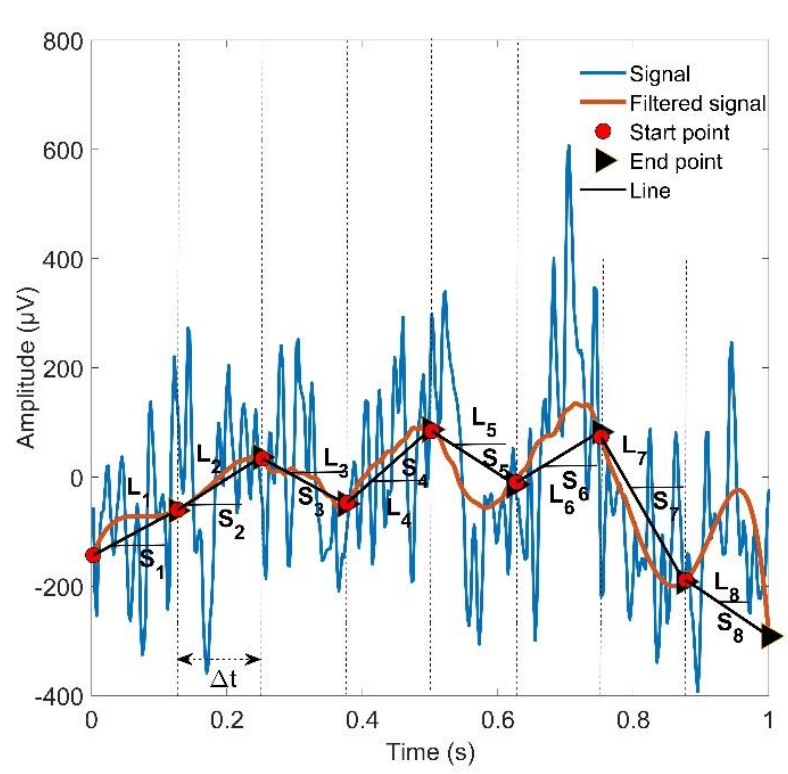

Figure 10. The slope of signal segments for subject-1, channel 3 and trial 20.

\subsection{Channel Selection}

In order to determine the effective channel subsets for classification, the labeled training data were divided into two groups as \% 90 pre-training and \% 10 pre-test data. Practically, optimal channel subsets were determined with the Cohen's Kappa coefficient [26], which is a statistical method that measures the reliability of the classification according to the pre-test data classification estimation success of an SVM classifier trained. Figure 11 is shown the flow diagram for calculating of optimal channel subsets.

As seen from Figure 11, first, all possible channel subsets were calculated and these channel subsets were classified with SVM classifier. The pre-training and pre-test success obtained from each classification result are called TRS and TES, respectively. A successful channel subset in classification requires a high degree of classification success. Therefore, it is expected that the maksimum Kappa is obtained for channel subset used in the classification. If the number of classification with the maximum Kappa is greater than 1, the channel subset of the classification which has the largest TS (TS = TRS + TES) select in maximum Kappa's.

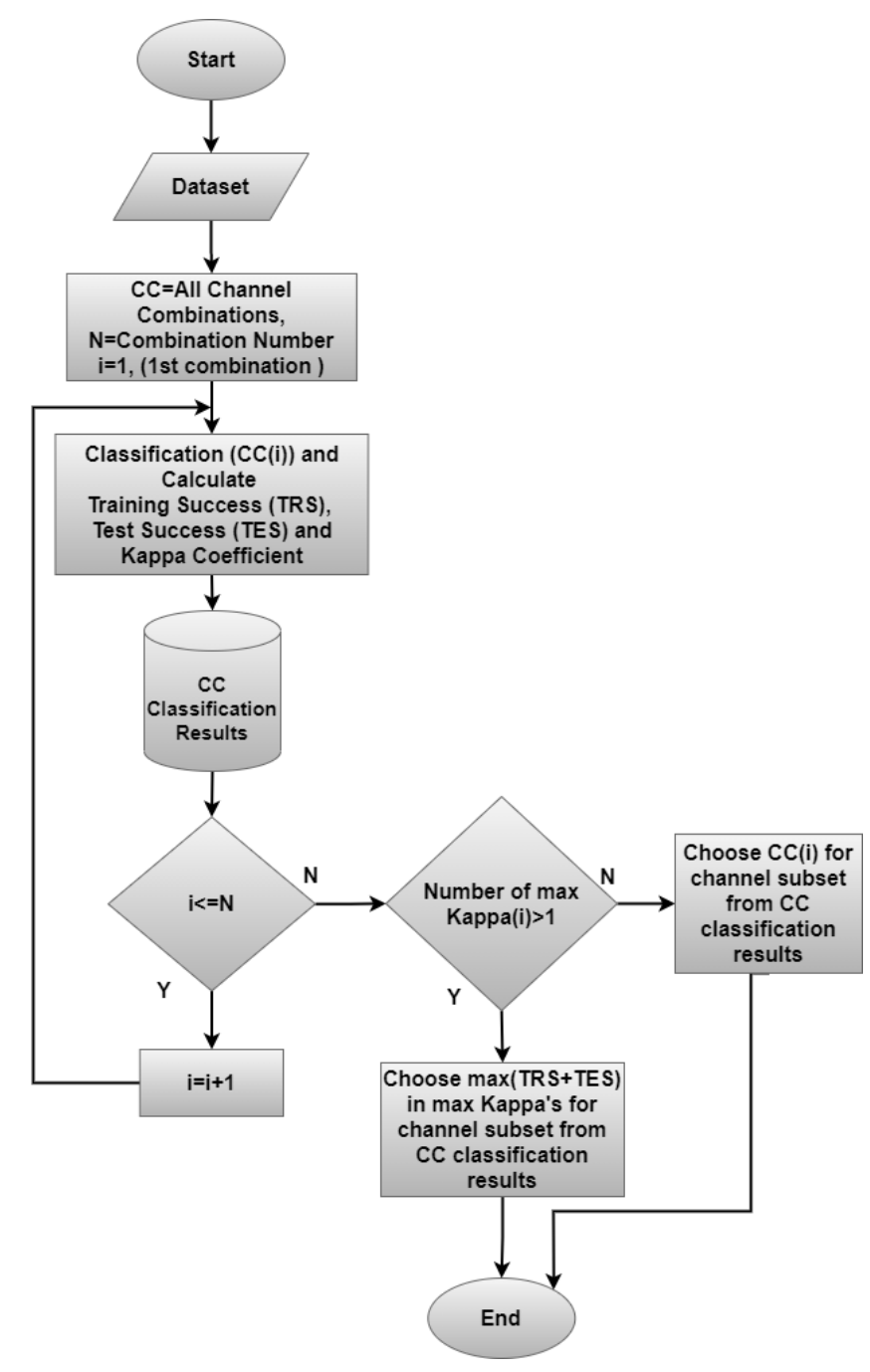

Figure 11. Flow diagram for determining optimal channel subsets.

\section{Classification}

\subsection{Support Vector Machine Classifier}

The Support Vector Machine (SVM) is state-of-the-art classification technique which used widely in digital signal processing [38]. The training data is given by Equation 6. $x(i) \in$ $R^{d}, \mathrm{y}_{\mathrm{i}} \in-1,+1$ and $d$ represents feature vector, class labels and dimension respectively.

$$
\left(x_{1}, y_{1}\right),\left(x_{2}, y_{2}\right), \ldots\left(x_{k}, y_{k}\right)
$$

When we think about the separating of the training data into two class, the optimal hyper plane $(w * x+b=0)$ in a space which seperates the two class is the one which maximizes the margin. The $f(p)$ determines that the $p$ belongs to which class by optimal $w$ and $b$ values $[15,16]$.

$$
f(p)=\operatorname{sgn}(\widehat{w}, p)+\hat{b}
$$

\section{Expeimental Results}

Using the extracted feature vectors and detected channel subsets, \% 90 of the labelled training data is used to train SVM classifier. The unlabeled evaluation dataset which consist 74 and 73 trials for subject- 1 and subject- 2 respectively, is classified by feature vectors obtained by SPW and SPS feature extraction 
methods. The classification results by using the SPW feature extraction method are given in Table 1 and Table 2 for subject- 1 and subject-2. The columns of the tables show the channel subsets and training accuracies, test accuracies, test Kappa coefficients, evaluation accuracies and evaluation Kappa coefficients of the classifications obtained with these channel subsets. The rows with the highest classification accuracies are highlighted. It is achieved $\% 49.17$ for subject-1 and \% 40.19 for subject-2 an evaluation accuracy by using the feature extraction method with Wavelet and proposed channel selection approach.

Table 1. Subject-1 Classification Results With Wavelet Features of Signal Segments.

\begin{tabular}{l|c|c|c|c|c}
\hline Channel Subset & Training Acc. $\%$ & Test Acc. $\%$ & Test Kappa & Eval. Acc. \% & Eval. Kappa \\
\hline 7,8 & 40.28 & 50.00 & 0.33 & 33.21 & 0.11 \\
\hline $1,4,9$ & 38.89 & 56.25 & 0.42 & 42.14 & 0.23 \\
\hline $1,4,9,10$ & 37.50 & 50.00 & 033 & 33.10 & 023 \\
\hline $1,4,6,9,10$ & 34.03 & 56.25 & 0.42 & 45.60 & 0.21 \\
\hline $2,4,7,8,9,10$ & 45.83 & 56.25 & 0.42 & 49.17 & 0.27 \\
\hline $3,4,6,7,8,9,10$ & 43.06 & 62.50 & 0.50 & 44.88 & 0.25 \\
\hline $1,3,4,6,7,8,9,10$ & 40.28 & 56.25 & 0.42 & 49.17 & 0.30 \\
\hline $1,3,4,5,6,7,8,9,10$ & 39.58 & 43.75 & 0.25 & 43.10 & 0.22 \\
\hline $1,2,3,4,5,6,7,8,9,10$ & 45.14 & 31.25 & 0.08 & & 2 \\
\hline
\end{tabular}

Table 2. Subject-2 Classification Results With Wavelet Features of Signal Segments.

\begin{tabular}{l|c|c|c|c|c}
\hline Channel Subset & Training Acc. \% & Test Acc. \% & Test Kappa & Eval. Acc. \% & Eval. Kappa \\
\hline 6,10 & 24.31 & 68.75 & 0.58 & 27.49 & 0.04 \\
\hline $4,7,10$ & 23.61 & 62.50 & 0.50 & 40.19 & 0.07 \\
\hline $1,4,6,10$ & 30.56 & 68.75 & 0.58 & 38.38 & 0.19 \\
\hline $2,4,6,7,10$ & 29.17 & 62.50 & 0.50 & 42.74 & 0.16 \\
\hline $1,4,5,6,8,9$ & 24.31 & 68.75 & 0.58 & 44.13 & 0.22 \\
\hline $1,4,5,6,8,9,10$ & 18.75 & 62.50 & 0.50 & 39.00 & 0.18 \\
\hline $1,4,5,6,7,8,9,10$ & 28.47 & 62.50 & 0.50 & 41.36 & 0.20 \\
\hline $1,2,3,4,6,7,8,9,10$ & 25.00 & 56.25 & 0.42 & 36.49 & \\
\hline
\end{tabular}

The classification results by feature vector obtained by using the proposed SPS method are given in Table 3. and Table 4. for subject-1 and subject-2. By using SPS feature vector extraction methods which produce a low dimensional feature vector, the highest classification accuracies are achieved \% 67.74 for subject-1 and \% 49.27 for subject-2 respectively. The Kappa coefficients are also calculated as 0.58 and 0.30 values which represents a medium and above harmony for these classifications.
The significant increase in the success for both subjects shows the consistency of the proposed SPS feature extraction method. When Table 3 and Table 4 examine it is observed that the classification performances of subject-1 and subject-2 are increased with channel subset $(2,4,7)$ and $(1,2,3,4,5,6,9)$. This can indicate that a motor imagery task coded in different parts for the brain for different subjects.

Table 3. Subject-1 Classification Results With The Slope of Signal Segments.

\begin{tabular}{l|c|c|c|c|c}
\hline Channel Subset & Training Acc. \% & Test Acc. \% & Test Kappa & Eval. Acc. \% & Eval. Kappa \\
\hline 4,7 & 53.47 & 68.75 & 0.58 & 55.48 & 0.39 \\
\hline $2,4,7$ & 56.25 & 75.00 & 0.67 & 67.74 & 0.53 \\
\hline $3,4,6,7$ & 48.62 & 87.50 & 0.83 & 56.67 & 0.46 \\
\hline $1,4,6,7,9$ & 59.72 & 87.50 & 0.83 & 58.45 & 0.39 \\
\hline $1,2,4,6,7,9$ & 55.56 & 87.50 & 0.83 & 49.88 & 0.42 \\
\hline $2,3,4,5,6,9,10$ & 60.42 & 81.25 & 0.75 & 63.45 & 0.30 \\
\hline $1,2,3,4,5,6,7,9$ & 55.56 & 81.25 & 0.75 & 50.71 & 0.31 \\
\hline $1,2,3,4,5,6,7,9,10$ & 53.47 & 75.00 & 0.67 & 51.67 & 0.31 \\
\hline $1,2,3,4,5,6,7,8,9,10$ & 60.42 & 62.50 & 0.50 & & \\
\hline
\end{tabular}


Table 4. Subject-1 Classification Results With The Slope of Signal Segments.

\begin{tabular}{l|c|c|c|c|c}
\hline Channel Subset & Training Acc. \% & Test Acc. \% & Test Kappa & Eval. Acc. \% & Eval. Kappa \\
\hline 8,9 & 44.44 & 43.75 & 0.25 & 35.80 & 0.14 \\
\hline $6,8,10$ & 41.67 & 50.00 & 0.33 & 33.37 & 0.10 \\
\hline $1,3,6,9$ & 35.42 & 68.75 & 0.58 & 40.46 & 28.03 \\
\hline $3,6,8,9,10$ & 40.28 & 62.50 & 0.50 & 32.82 & 0.21 \\
\hline $1,2,3,6,8,10$ & 36.81 & 62.50 & 0.50 & 49.27 & 0.11 \\
\hline $1,2,3,4,5,6,9$ & 37.50 & 56.25 & 0.42 & 42.12 & 0.30 \\
\hline $1,2,3,5,6,8,9,10$ & 37.50 & 62.50 & 0.50 & 40.66 & 0.20 \\
\hline $2,3,4,5,6,7,8,9,10$ & 40.28 & 50.00 & 0.33 & 37.76 & 0.18 \\
\hline $1,2,3,4,5,6,7,8,9,10$ & 38.19 & 50.00 & 0.33 & & 0.14 \\
\hline
\end{tabular}

Table 5 demonstrates the comparison of the overall accuracy between existing studies and our study. The highest accuracy of the dataset- 3 is achieved by our proposed SPS feature extration method.

Table 5. Comparison of Overall Accuracy Between Existing Studies And Our Study

\begin{tabular}{|l|c|c|c|}
\hline \multicolumn{1}{|c|}{ Participants } & $\begin{array}{c}\text { S1 } \\
\text { Acc. } \\
\text { \% }\end{array}$ & $\begin{array}{c}\text { S2 } \\
\text { Acc. } \\
\text { \%o }\end{array}$ & $\begin{array}{c}\text { Average } \\
\text { Acc. \% }\end{array}$ \\
\hline Sardouie and Shamsollahi & 59.50 & 34.30 & 46.90 \\
\hline Li et al. & 31.10 & 19.20 & 25.10 \\
\hline Montazeri and Shamsollahi & 16.20 & 31.50 & 23.90 \\
\hline Wang and Zhang & 23.00 & 17.80 & 20.40 \\
\hline Our study & 67.74 & 49.27 & 58.51 \\
\hline
\end{tabular}

\section{Conclusion}

In this study, novel and practical methods are proposed for determining the distinctive features and detecting effective channel subsets in the multi channel classification systems such as EEG. The feature vectors obtained by using the proposed methods were classified for each method with the Support Vector Machine classifier. The classification results of the proposed methods are given comparatively. By using proposed Signal Path Slope (SPS) feature extraction method based on the Savitzky Golay (S-G) filter, the highest classification accuracies of \% 67.74 and $\% 49.27$ for subject-1 and subject-2 respectively were achieved above the competition results. The Kappa coefficients are also calculated as 0.53 and 0.30 values which represents a medium and above harmony for these classifications. The classification accuracies achieved in the study are increased by $\%$ 8.24 for subject-1 and \% 14.97 for subject-2 when compared average of the competition results. The significant increase in the success for both subjects shows the consistency of the proposed methods. The another efficacy of the proposed SPS approach is reducing the dimensionality of the feature vectors. The feature vector was generated with only slope feature calculated from each signal segment for a channel. On the other hand, the classification performance of subject-1 and subject- 2 are increased with different channel subsets. This can indicate that a motor imagery task coded in different parts for the brain for different subjects. By this study, it was observed that there was a subject-specific signal pattern related to motor imagery tasks in the brain. This pattern was successfully classified by using the proposed methods.

\section{References}

[1] G. Pfurtscheller, C. Neuper, N. Birbaumer, "Human braincomputer interface (BCI)," FIn:Riehle A, Vaadia E, editors. A distributed system for distributed functions, Motor Cortex in Voluntary Movements,pp. 367-401, 2005.

[2] G. S. Sagee, S. Hema, "EEG feature extraction and classification in multiclass multiuser motor imagery brain computer interface using Bayesian Network and ANN," Intelligent Computing, Instrumentation and Control Technologies (ICICICT) International Conference on. IEEE, 2017.

[3] H. K. Lee, Y.S. Choi, “A convolution neural networks scheme for classification of motor imagery EEG based on wavelet time-frequecy image," Intelligent Computing, Information Networking (ICOIN) International Conference on. IEEE, 2018.

[4] N. Lu , T. Li, X. Ren, H. Miao, “A deep learning scheme for motor imagery classification based on restricted Boltzmann machines," IEEE Trans Neural Systems Rehabil Eng, vol. 25, pp. 566-76, 2017.

[5] A. S. Al-Fahoum, A. A. Al-Fraihat, "Methods of EEG signal features extraction using linear analysis in frequency and time-frequency domains," ISRN neuroscience, January 2014.

[6] C.Y. Chen, C. W. Wu, C. T. Lin, S. A. Chen, "A novel classification method for motor imagery based on braincomputer interface," Neural Networks (IJCNN), July 2014.

[7] P. Gaur, R. B. Pachori, H. Wang, G. Prasad, "Empirical mode decomposition based filtering method for classification of motor-imagery EEG signals for enhancing brain-computer interface," Neural Networks (IJCNN), July 2015.

[8] J. S. Kirar, R. K. Agrawal, "Relevant feature selection from a combination of spectraltemporal and spatial features for classification of motor imagery EEG,'J. Med Syst, pp.47-78, 2018.

[9] T. Chivalai, "Increase performance of four-class classification for motorimagery based brain-computer interface," Computer, information and telecommunication systems (CITS), July 2014.

[10] T. Alotaiby, F. El-Samie, S. Alshebeili, I. Ahmad, “A review of channel selectionalgorithms for EEG signal processing," EURASIP J. Adv. Signal Process, vol. 1, pp. 66-86, 2015. 
[11] E. Erkan, I. Kurnaz, "A study on the effect of psychophysiological signal features on classification methods," Measurements in Biology and Medicine, vol. 101, pp. 45-52, January 2017.

[12] H. Choubey, A. Pandey, "A combination of statistical parameters for the detection of epilepsy and EEG classification using ANN and KNN classifier," SIViP, vol. 15, pp. 475-483, 2021.

[13] R. Aler, I. M. Galvan, J. M. Valls, “Transition detection for brain computer interface classification," International joint conference on biomedical engineering systems and technologies, Berlin, January 2009.

[14] R. Aler, I. M. Galvan, J. M. Valls, "Evolving spatial and frequency selection filters for brain-computer interfaces," Evolutionary Computation (CEC), July 2010.

[15] C. Schuldt, I. Laptev, B. Caputo, "Recognizing Human Actions: A Local “ SVM Approach," In Proc. CVPR, vol. 3, pp. 32-36, March 2004.

[16] A. Anuragi, D. S. Sisodia, "Empirical wavelet transform based automated alcoholism detecting using EEG signal features," Biomedical Signal Processing and Control, vol. 57, pp. 1746-36, 2020.

[17] S.Z. Zahid, M. Aqil, M. Tufail, M.S. Nazir, "Online Classification of Multiple Motor Imagery Tasks Using Filter Bank Based Maximum-aPosteriori Common Spatial Pattern Filters,'IRBM, pp.141-150, 2020.

[18] P. Gaur, H. Gupta, A. Chowdhury, K. McCreadie, R. B. Pachori, H. Wang, "A Sliding Window Common Spatial Pattern for Enhancing Motor Imagery Classification in EEGBCI,'IEEE Transactions on Instrumentation and Measurement, vol. 70, pp.1-9, 2021.

[19] M. Hamedi, S. H. Salleh, A. M. Noor, I. MohammadRezazadeh, "Neural network-based three-class motor imagery classification using time-domain features for BCI applications," Region 10 Symposium, pp.14-16, April 2014.

[20] S. K. Agarwal, S. Shah, R. Kumar, "Classification of mental tasks from EEG data using backtracking search optimization based neural classifier," Neurocomputing, vol. 166, pp. $397-$ 403, 2015.

[21] J. Zhang, C. Yan, X. Gong, "Deep convolutional neural network for decoding motor imagery based brain computer interface, Signal Processing," Communications and Computing (ICSPCC), October 2017.

[22] S. Sakhavi, C. Guan, S. Yan, "Parallel convolutional-linear neural network for motor imagery classification, Signal Processing Conference (EUSIPCO), 2015.

[23] W. Ko, J. Yoon, E. Kang, E. Jun, J.S. Choi, H.I. Suk, “Deep recurrent spatio-temporal neural network for motor imagery based BCI," Braincomputer interface (BCI), January 2018.

[24] S. Sakhavi, C. Guan, S. Yan, "Learning temporal information for brain-computer interface using convolutional neural networks," . IEEE Transactions on Neural Networks and Learning Systems, pp. 5619-5629, March 2018.

[25] A. Savitzky, M. J. E. Golay, "Smoothing and Differentiation of Data by Simplified Least Squares Procedures," Anal Chem., vol. 36, pp. 1627- 1639, 1964.
[26] S. Julius, C. C. Wright, "The Kappa Statistic in Reliability Studies: Use, Interpretation, and Sample Size Requirements," Physical Therapy, vol. 85, pp. 257-268, March 2005.

[27] S. H. Sardouie, M. B. Shamsollahi, "Selection of efficient features for discrimination of hand movements from MEG using a BCIcompetition IV dataset," Frontiers in Neuroscience, vol. 6(42), July 2012.

[28] M. Tangermann, K. R. Muller,A. Aertsen, N. Birbaumer, C. B, C. “ Brunner, R. Leeb, C. Mehring,1 K. J. Miller, G. R. Muller-Putz, G. " Nolte, G. Pfurtscheller, H. Preissl, G. Schalk, A. Schlogl, C. Vidaurre, “' S. Waldert, B. Blankertz, "Review of the BCI competition IV," Frontiers in Neuroscience, vol. 6(55), January 2012.

[29] A. N. Belkacem, H. Hirose, N. Yoshimura, D. Shin, Y. Koike, "Classification of Four EyeDirections from EEG Signals for Eye-MovementBased Communication Systems," Journal of Medical and Biological Engineering, vol. 34(6), pp. 581-508, October 2013.

[30] H. Li, R. Lan, N. Peng, J. Sun, Y. Zhu, "High resolution melting curve analysis with MATLAB-based program," Measurement, vol. 90, pp. 178-186, Agust 2016.

[31] S. Hargittai, "Savitzky-Golay least-squares polynomial filters in ECG signal processing," Computers in Cardiology, September 2005

[32] S. Agarwa, A. Rani, V. Singh, A. .P.Mittal, "EEG signal enhancement using cascaded S-Golay filter," Biomedical Signal Processing and Control, vol. 36, pp. 194-204, July 2017.

[33] V. Gandhi, G. Prasad, D. Coyle, L. Behera, T. M. McGinnity, "Quantum Neural Network-Based EEG Filtering for a BrainComputer Interface," IEEE Transactions on Neural Networks and Learning Systems, vol. 25(2), pp. 278-288, Agust 2013.

[34] B. Kaur, D. Singh, P. P. Roy, “A Novel framework of EEGbased user identification by analyzing music-listening behavior," Multimedia Tools and Applications, vol. 76, pp. 25581-25602, December 2017.

[35] M. Alam, S. Basak, Md. I. Islam, "Fingerprint Detection Applying Discrete Wavelet Transform on ROI," International Journal of Scientific and Engineering Research, vol. 3(6), pp. 1360-1364, June 2012.

[36] M. Balasubramanian, S. Palanivel, V.Ramalingam, "Real time face and mouth recognition using radial basis function neural networks," Expert Systems with Applications, vol. 36(3), pp. 6879-6888, April 2009.

[37] S. Madabusi, V. Srinivas, S. Bhaskaran, M. Balasubramanian, "Online and off-line signature verification using relative slope algorithm," Measurement Systems for Homeland Security, Contraband Detection and Personal Safety, March 2005.

[38] L. Wolf, A. Shashua, "Kernel principal angles for classification machines with applications to image sequence interpretation," In Proc. CVPR, vol. 1, pp. 635-640, March 2003. 